\title{
TEXT TO SPEECH BERBASIS NATURAL LANGUAGE PADA APLIKASI PEMBELAJARAN TENSES BAHASA INGGRIS
}

\author{
Amak Yunus E.P, email:amakyunus@yahoo.com \\ Danang Aditya Nugraha, email: d4n4ng.adty@gmail.com \\ Jurusan Teknik Informatika di Universitas Kanjuruhan Malang
}

\begin{abstract}
Abstrak-Bahasa adalah sebuah cara berkomunikasi secara sistematis dengan menggunakan suara atau simbolsimbol yang memiliki arti, yang diucapkan melalui mulut. Bahasa juga ditulis dengan mengikuti kaidah yang berlaku. Salah satu bahasa yang banyak digunakan di belahan dunia adalah Bahasa Inggris. Namun ada beberapa kendala apabila kita belajar kepada seorang guru atau instruktur. Waktu yang diberikan seorang guru, terbatas pada jam sekolah atau les saja. Bila siswa pulang sekolah atau les, maka yang bersangkutan harus belajar bahasa Inggris secara mandiri.

Dari permasalahan di atas, muncul sebuah ide tentang bagaimana membuat sebuah penelitian yang berkaitan dengan pembuatan aplikasi yang mampu memberikan pengetahuan kepada siswa tentang bagaimana belajar bahasa Inggris secara mandiri baik dari perubahan kalimat postif menjadi kalimat negatif dan kalimat tanya. Disamping itu, aplikasi ini juga mampu memberikan pengetahuan tentang bagaimana mengucapkan kalimat dalam bahasa Inggris.

Pada intinya kontribusi yang dapat diperoleh dari hasil penelitian ini adalah pihak terkait dari tingkat SMP sampai dengan SMU/SMK, dapat menggunakan aplikasi text to speech berbasis natural language processing untuk mempelajari tenses pada bahasa Inggris. Aplikasi ini dapat memperdengarkan kalimat-kalimat pada bahasa inggris dan dapat menyusun kalimat tanya dan kalimat negatif berdasarkan kalimat positifnya dalam beberapa tenses bahasa Inggris.
\end{abstract}

Kata Kunci : Natural language processing, Text to speech

\section{LATAR BELAKANG}

Bahasa adalah sebuah cara berkomunikasi secara sistematis dengan menggunakan suara atau simbolsimbol yang memiliki arti, yang diucapkan melalui mulut. Bahasa juga ditulis dengan mengikuti kaidah yang berlaku. Salah satu bahasa yang banyak digunakan di belahan dunia adalah Bahasa Inggris.

Di masa kemerdekaan ini, penggunaan bahasa Inggris tidak kalah pentingnya. Beberapa alasan mengapa Bahasa Inggris masih dirasakan penting di antaraanya adalah: pertama, Bahasa Inggris digunakan pada perusahaan-perusahaan asing, tentu saja hal ini menuntut agar para pekerja mampu berkomunikasi antara satu sama lain. Kedua, Ilmu pengetahuan sekarang ini banyak yang berkiblat ke dunia barat. Banyak sumber ilmu berupa buku, pidato, acara seminar internasional, halaman internet yang menggunakan bahasa Inggris. Ketiga, Bahasa Inggris merupakan salah satu cara menguasai teknologi dan Informasi. Komputer, baik hardware maupun software dibuat dengan panduan Bahasa Inggris. Beberapa saat yang lalu, hacker anonymous Indonesia berhasil mengalahkan hacker Asing (merdeka.com, 2013). Hal ini tentu saja memerlukan pemahaman bahasa Inggris yang cukup baik karena panduan software yang diciptakan saat ini banyak yang menggunakan Bahasa Inggris.

Salah satu bagian penting dari Bahasa Inggris adalah mengenai tenses. Tenses merupakan adalah bentuk kata kerja dalam bahasa Inggris untuk menunjukkan waktu (sekarang, masa depan, atau masa lalu) terjadinya suatu perbuatan atau peristiwa) (Panca,2008).

Berdasarkan uraian tinjauan pustaka di atas, maka apabila seseorang menginginkan belajar Bahasa Inggris, khususnya mengenai tenses secara mandiri, perlu sebuah perangkat lunak yang mampu merubah kalimat positif menjadi kalimat negatif dan kalimat tanya. Serta mampu memberikan contoh pengucapan kalimat-kalimat tersebut.

Terdapat sebuah metode pada teknologi informatika untuk merubah sebuah kalimat positif menjadi kalimat negatif dan kalimat tanya. Metode tersebut dikenal dengan Natural language processing. Natural language processing adalah sebuah metode komputasi yang dapat menerjemahkan bahasa alami manusia (Steven Bird, 2009).

Selain itu juga terdapat teknologi yang dapat merubah tulisan menjadi suara. Teknologi ini disebut 
dengan text to speech. Text to speech adalah sebuah teknologi suara tiruan manusia yang dapat membantu mansusia dalam membaca secara otomatis dokumen yang diberikan (Margareth, 2007).

\section{A. Tenses dalam Bahasa Inggris}

Bahasa Inggris merupakan bahasa internasional yang dipakai di seluruh dunia. Seperti bahasa-bahasa lainnya di dunia, Bahasa Inggris juga memiliki aturan-aturan tertentu dalam mengekspresikan sebuah kalimat (Panca,2008). Pada umumnya, tata bahasa Bahasa Inggris memiliki pola S-P-O, seperti kata "I love you", kalimat ini adalah kalimat berita (affirmative). Dari kalimat berita ini, dapat dibuat ke dalam suatu kalimat pertanyaan. Dari kata "I love you", dapat dibuat dalam bentuk kalimat pertanyaan "Who loves you".

Untuk dapat membuat sistem interaktif, dibutuhkan pengetahuan tentang tata bahasa Inggris, terutama yang berkaitan dengan tenses. Dalam Bahasa Inggris, dikenal lebih dari 10 tenses yang sebaiknya perlu diketahui. Hal perlu diketahui karena masing-masing tenses tersebut memiliki karakteristik yang berbeda, tergantung pada tensesnya masingmasing. Contoh Tense yang ada dapat dilihat pada tabel 1:

\begin{tabular}{|c|c|c|c|}
\hline Tense & $\begin{array}{l}\text { Affirmative/Negative/Que } \\
\text { stion }\end{array}$ & Contoh: & $\begin{array}{l}\text { Signal } \\
\text { Words }\end{array}$ \\
\hline $\begin{array}{l}\text { Simple } \\
\text { Present Tense }\end{array}$ & $\begin{array}{l}\text { A: } \mathrm{S}+(\mathrm{V})+\mathrm{O} \\
\mathrm{N}: \mathrm{S}+\text { do/does }+ \text { not }+(\mathrm{V}) \\
+\mathrm{O} \\
\mathrm{Q}: \text { Do/does }+\mathrm{S}+\mathrm{V}+\mathrm{O}\end{array}$ & $\begin{array}{l}\text { A: I want to eat } \\
\mathrm{N} \text { : I don't want to } \\
\text { eat } \\
\text { Q: Do you want to } \\
\text { eat? }\end{array}$ & $\begin{array}{l}\text { Always, } \\
\text { every ..., } \\
\text { never, } \\
\text { normally, } \\
\text { often, } \\
\text { seldom, } \\
\text { sometimes, } \\
\text { usually }\end{array}$ \\
\hline $\begin{array}{ll}\text { Simple } & \text { Past } \\
\text { Tense } & \end{array}$ & $\begin{array}{l}\mathrm{A}: \mathrm{S}+\mathrm{V} 2+\mathrm{O} \\
\mathrm{N}: \mathrm{S}+\mathrm{did}+\text { not }+\mathrm{V}+\mathrm{O} \\
\mathrm{Q}: \mathrm{Did}+\mathrm{S}+\mathrm{V}+\mathrm{O}\end{array}$ & $\begin{array}{l}\text { A:I sat on the chair } \\
\text { N:I didn't sit on } \\
\text { the chair } \\
\text { Q:Did I sit on the } \\
\text { chair }\end{array}$ & $\begin{array}{l}\text { Yesterday, } \\
\text { Last Month, } \\
\text { In } 1945\end{array}$ \\
\hline
\end{tabular}

\section{B. Natural language processing}

Natural language processing (NLP) adalah suatu metode yang digunakan dalam mengenali ucapan, dan tulisan manusia. Metode ini membutuhkan proses pengenalan bahasa tertentu, di samping itu juga perlu memiliki pendekatan teknis tertentu. Sampai saat ini NLP masih dalam proses pengembangan. Tentu saja perlu sebuah cara tertentu agar komputer tersebut dapat mengenali ucapan maupun tulisan manusia. Namun pada makalah ini, pembahasan hanya dibatasi pada tulisan saja.

Pada penelitian ini, bahasa yang diteliti adalah Bahasa Inggris, mengingat bahwa bahasa ini merupakan bahasa internasional. Selain itu, Bahasa Inggris juga memiliki aturan yang jelas dan cukup banyak dimengerti oleh para pemakainya di penjuru dunia (Steven,2009).

\section{Text to speech}

Sebuah text to speech merupakan sebuah tiruan suara manusia yang berasal dari komputer yang dapat membaca tulisan secara otomatis, dimana tulisan tersebut bisa berasal dari stream data, Optial character recognition, maupun tulisan yang berasal dari file. Sebuah suara tiruan dapat diimplementasikan melalui hardware maupun software. Teknologi Text to speech telah mengalami perkembangan yang cukup cepat dan sekarang pun telah tersedia dalam versi gratis maupun komersil.

Suara tiruan biasanya berupa penggabungan suara alami manusia yang diucapkan perkata, ataupun dari penggabungan kata-kata yang terdapat di dalam suata pelatan seperti komputer, handphone. Pada penggunaan text to speech perlu diperhatikan masalah ucapan agar lebih terlihat alami dan mudah dimengerti (D. Sasirekha, 2012).

\section{DESAIN SISTEM}

Pada tahap ini, setiap bagian dari analisa kebutuhan sistem akan didesain sesuai dengan harapan pengguna. Desain algoritma yang berupa flowchart pada software ini terdapat pada Gambar1.

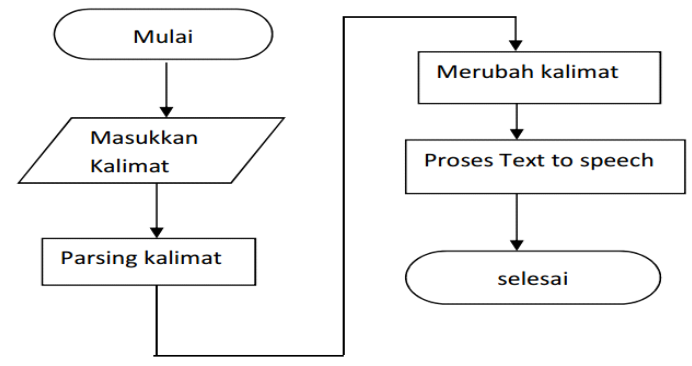

Gambar 1. Desain Sistem

Sedangkan desain antar muka yang dilakukan adalah dengan membuat antar muka pada Gambar 2.

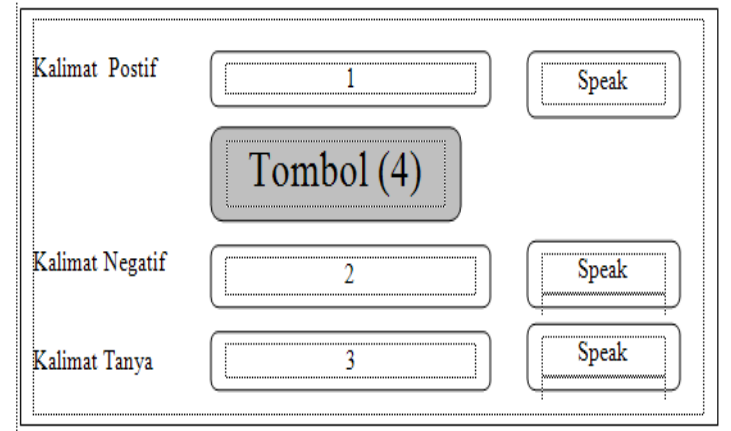

Gambar 2. Desain Antar Muka 
Tabel 2. Keterangan Desain

\begin{tabular}{|l|l|l|}
\hline No & Item & Keterangan \\
\hline 1 & JtextField & Untuk memasukkan kalimat positif / berita \\
\hline 2 & JtextField & Untuk menampilkan kalimat negatif \\
\hline 3 & JtextField & Untuk menampilkan kalimat tanya \\
\hline 4 & Jtogglebutton & $\begin{array}{l}\text { Untuk mentrigger tampilan pada jtextfield 2 } \\
\text { dan jtextfield3 }\end{array}$ \\
\hline
\end{tabular}

\section{IMPELEMENTASI}

Pada tahap ini akan dilakukan pemrograman. Desain yang telah dibuat akan dimasukkan pada tahap ini. Pada tahap ini, implementasi sistem akan menggunakan suatu bahasa pemrograman yaitu bahasa Java. Sedangkan IDE yang digunakan adalah netbeans versi 1.73 pada Gambar 3 .

\section{PERCOBAAN}

Pada tahap ini akan dilakukan uji coba pada program yang telah dibuat dapat dilihat pada Gambar 4. Pada saat tombol change ditekan, maka akan muncul kalimat negatif dan kalimat tanya. Dan di sebelah kanan masing-masing textbox terdapat tombol untuk mengucapkan kalimat-kalimat tersebut

Di bawah ini adalah beberapa fungsi yang dibuat untuk merubah kalimat postif menjadi kalimat negatif dan kalimat tanya.

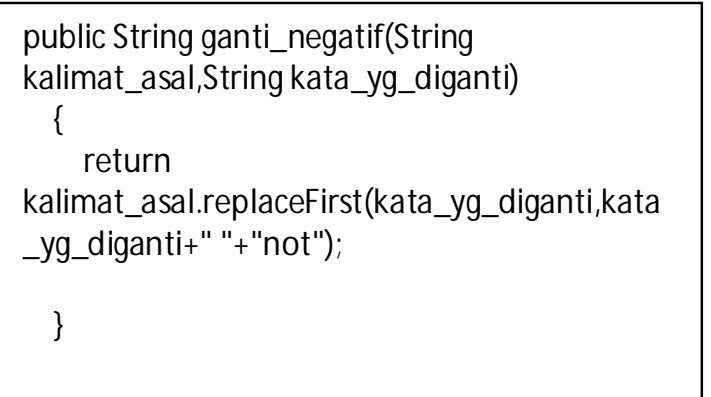

public String ganti_tanya(String

kalimat_asal,String kata_yg_diganti)

\{String tampung="';

tampung=kalimat_asal.replaceFirst $(k a$

ta_yg_diganti, "');

tampung=tampung.replaceFirst(tampung,

kata_yg_diganti+" "+tampung);

$$
\text { return tampung; \} }
$$

\section{ANALISIS DATA}

Metode analisa data pada penelitian ini menggunakan metode blackbox. Metode ini menerapkan aturan apakah semua yang telah dirancang telah sesuai dengan harapan pengguna. Pada penelitian ini, analisa datanya dapat dilihat pada Tabel 3.

Dari hasil pengujian di atas, maka hasil yang bisa dicapai oleh sistem ini adalah sistem telah dapat melakukan fungsinya sesuai harapan pengguna.
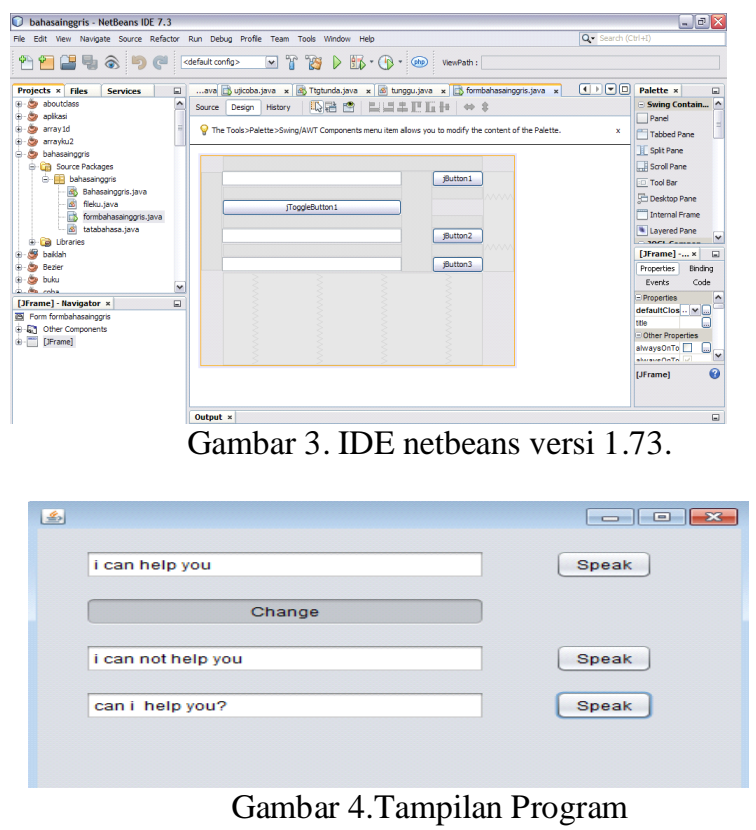

Tabel 3. Analis Data

\begin{tabular}{|l|l|l|}
\hline$]$ & Item & Hasil Analisa \\
\hline 1 & $\begin{array}{l}\text { pengguna dapat } \\
\text { memasukkan kata }\end{array}$ & Sudah sesuai \\
\hline 2 & $\begin{array}{l}\text { Pengguna dapat } \\
\text { melakukan klik } \\
\text { pada tombol }\end{array}$ & Sudah sesuai \\
\hline 3 & $\begin{array}{l}\text { Sistem dapat } \\
\text { menampilkan } \\
\text { kalimat tanya }\end{array}$ & Sudah sesuai \\
\hline 4 & $\begin{array}{l}\text { Sistem dapat } \\
\text { menampilkan } \\
\text { kalimat negatif }\end{array}$ & Sudah sesuai \\
\hline 5 & $\begin{array}{l}\text { Sistem dapat } \\
\text { mengucapkan } \\
\text { kalimat positif }\end{array}$ & Sudah sesuai \\
\hline 6 & $\begin{array}{l}\text { Sistem dapat } \\
\text { mengucapkan } \\
\text { kalimat positif }\end{array}$ & Sudah sesuai \\
\hline 7 & $\begin{array}{l}\text { Sistem dapat } \\
\text { mengucapkan } \\
\text { kalimat positif }\end{array}$ & Sudah sesuai \\
\hline
\end{tabular}




\section{KESIMPULAN DAN SARAN}

A. Kesimpulan

Kesimpulan yang bisa diambil dari penelitian ini adalah sistem yang dibuat telah melalui beberapa tahap yaitu: pengumpulan data, desain sistem, impelementasi, dan pengujian (testing).

\section{B. Saran}

Beberapa saran yang perlu disampaikan dari penelitian ini adalah:

1. Sebaiknya sistem dapat mengucapkan kata-kata dalam bahasa lain dengan lebih baik

2. Sistem dapat dikembangkan dengan cara speech recognition

\section{DAFTAR PUSTAKA}

[1] Bird, Steven, "Introduction to Natural Language Processing”, www.ldc.upenn.edu/sb/nltk-bookpart1.pdf, 2006 (Terakhir diakses tanggal 5 Maret 2014)

[2] http://learnenglish.britishcouncil.org/en/englishgrammar/verbs/modal-verbs/will-or-would
[3] http://www.ego4u.com/en/cramup/grammar/tenses, Terakhir diakses tanggal 5 Maret 2014

[4]

[5] http://www.myenglishpages.com/site_php_files/g rammar-lesson-modals.php

[6] http://www.talkenglish.com/Grammar/auxiliaryverbs-will-would-shall-should.aspx

[7] Huddleston, Rodney, "A Students' introduction to English Grammar, Cambridge University, 2005

[8] Liddy, E. D. In Encyclopedia of Library and Information Science, $2^{\text {nd }}$ Ed. Marcel

[9]Decker,

Inc.,www.cnlp.org/publications/03nlp.lis.encyclo pedia.pdf, (Terakhir diakses tanggal 5 Maret 2014)

[10] Rindflesch, Thomas C., "Natural Language Processing”, 1993 